\title{
FERTILIDADE DE SOLOS CONSTRUÍDOS EM ÁREAS DE MINERAÇÃO DE CARVÃO NA REGIÃO SUL DE SANTA CATARINA ${ }^{1}$
}

\author{
Samuel Costa² e Jairo José Zocche ${ }^{3}$
}

\begin{abstract}
RESUMO - Com o objetivo de analisar a fertilidade de solos construídos sobre áreas mineradas de carvão a céu aberto ( $28^{\circ} 35^{\prime} 50^{\prime \prime} \mathrm{S}$ e $49^{\circ} 25^{\prime} 26^{\prime}$ 'W) no Município de Siderópolis, SC, foram escolhidas duas áreas recuperadas em épocas distintas: área IV em 2002 e área VI em 2003. No centro de cada área foi estabelecida uma transecção de $100 \mathrm{~m}$ de comprimento, em que foram lançadas alternadamente à direita e à esquerda, a intervalos de $10 \mathrm{~m}$, transecções perpendiculares de $20 \mathrm{~m}$, em que foram coletadas nove amostras de solo (0 $-0,2 \mathrm{~m}$ ). As nove amostras de cada grupo de dois transectos consecutivos foram reunidas em uma amostra composta, reduzindo o universo amostral de 90 para cinco amostras de solo de cada área. Foram analisados os teores de argila, pH, fósforo, potássio, matéria orgânica, alumínio, cálcio, magnésio, $\mathrm{H}+\mathrm{Al}$, soma das bases, CTC e saturação por bases. Em ambas as áreas, o teor de argila foi enquadrada na classe 3, o teor de matéria orgânica foi baixa, o pH e V\% muito baixos, o Mg variou de médio a alto, a SB variou de baixa a média e a CTC foi considerada alta. Na área IV, o teor de $\mathrm{P}$ foi baixo, e o de Ca variou de médio a baixo, enquanto na área VI o teor de $\mathrm{P}$ variou de baixo a médio, e o de Ca foi baixo. Embora tenham sido observadas diferenças entre alguns dos parâmetros analisados, essas não foram severamente afetadas pelo tempo de recuperação das duas áreas.
\end{abstract}

Palavras-chave: Carvão, áreas degradadas e recuperação ambiental.

\section{SOIL FERTILITY OF COAL MINING RECLAIMED AREAS IN THE SOUTHERN REGION OF SANTA CATARINA}

\begin{abstract}
With the objective of analyzing the fertility of soils built over open pit coal mining areas (28 $35^{\prime} 50^{\prime \prime}$ $S$ e 49 $25^{\prime} 26^{\prime \prime} W$ ) in the city of Siderópolis (SC), two areas of different reclamation ages were selected: area $I V$ and area VI, reclaimed in 2002 and 2003, respectively. A $100 \mathrm{~m}$ transection was established in the center of each area, where perpendicular $20 \mathrm{~m}$ transects were tossed at regular intervals of $10 \mathrm{~m}$, alternating to the right and to the left, and nine soil samples were collected $(0-0,2 \mathrm{~m})$. The nine samples of each group of two consecutive transects were gathered into a compound sample, reducing the sampling universe from 90 to 5 samples of soil for each area. The contents of clay, $\mathrm{pH}$, Phosphorus, Potassium, organic matter, Aluminum, Calcium, Manganese, $H+A l$, base sum, CTC and base saturation were analyzed. In both areas, the content of clay fell into class three category, the content of organic compound was low, the pH and V\% significantly low. Manganese varied from medium to high, BS varied from low to medium and CTC was considered high. In area $I V$, the content of $P$ was low and Ca varied from medium to low, while in area VI the content of $P$ varied from low to medium and Ca was low. Although differences had been observed among some of the parameters analyzed, they were not severely affected by the reclaimed time of the two areas.
\end{abstract}

Keywords: Coal, degraded areas and environmental reclamation.

\footnotetext{
${ }^{1}$ Recebido em 30.08.2007 e aceito para publicação em 29.05.2009.

2 Programa de Pós-Graduação em Ciências Ambientais da Universidade Extremo Sul Catarinense (UNESC). E-mail: <samuelclemes@hotmail.com>.

${ }^{3}$ Departamento de Ciências Biológicas da UNESC. E-mail: <jjz@ unesc.net>.
} 


\section{INTRODUÇÃO}

A explotação de carvão mineral caracterizou-se, desde o início, como atividade econômica fundamental ao desenvolvimento de toda a região sul de Santa Catarina (DE LUCA; GASTALDON, 1999). Apesar de sua importância, a extração, o beneficiamento e a utilização desse recurso energético são atividades potencialmente poluidoras, representando elevado risco de comprometimento ambiental, como a alteração da paisagem, das comunidades faunísticas e florísticas e contaminação do solo, do ar e dos recursos hídricos, além da interferência no microclima e na ciclagem de nutrientes (SANCHEZ e FORMOSO, 1990; GAIVIZZO et al., 2000; GAIVIZZO et al., 2002).

Em Santa Catarina, a explotação de carvão mineral é realizada em minas subterrâneas e a céu aberto (ALEXANDRE, 1999). No processo de mineração a céu aberto, a remoção das camadas é feita de forma desordenada (DIAS, 1998), provocando a sua inversão e gerando pilhas de materiais geológicos que têm na sua base a camada fértil do solo (DE LUCA e GASTALDON, 1999), causando, portanto, perda de solo fértil (SANCHEZ e FORMOSO, 1990) e sua degradação (ARAÚJO et al., 2005).

A legislação brasileira, conforme a Resolução CONAMA 001/86 (BRASIL, 1986), preconiza há muito tempo a obrigatoriedade da recuperação de áreas degradadas pela extração de recursos naturais. Essa recuperação passa pela recomposição topográfica e paisagística, assim como pela reconstrução do solo, a fim do restabelecimento do equilíbrio ecológico.

Os solos construídos são feições topográficas de áreas que sofreram processo de mineração a céu aberto (KÄMPF et al., 1997; PINTO, 1997; KÄMPF et al., 2000), que devem proporcionar condições para o desenvolvimento da vegetação (PINTO, 1997; GONÇALVES et al., 2003). Durante o processo de construção de um solo, são necessários a avaliação e monitoramento constante das condições químicas, especialmente a sua fertilidade (MIAO e MARRS, 2000), uma vez que ela indica disponibilidade e presença de elementos tóxicos às plantas (SCIVITTARO e PILLON, 2006).

Poucas são as informações morfológicas ou químicas existentes acerca dos solos construídos após a mineração de carvão a céu aberto, destacando-se os trabalhos de Kämpf et al. (1997), Pinto (1997) e Kämpf et al. (2000), desenvolvidos no Rio Grande Sul; e o de Campos et al. (2003), em Santa Catarina.

R. Árvore, Viçosa-MG, v.33, n.4, p.665-674, 2009
Considerando que fertilidade do solo reflete a distribuição e abundância de espécies vegetais (RODRIGUES et al., 2007) e que há escassez de trabalhos relacionados a solos construídos sobre áreas de mineração de carvão, o objetivo deste estudo foi analisar a fertilidade de solos construídos em áreas mineradas de carvão a céu aberto, na Bacia Carbonífera de Santa Catarina.

\section{MATERIAL E MÉTODOS}

\section{1. Área de estudo}

O estudo foi desenvolvido no lavador de carvão da Mina do Trevo (28 $35^{\prime} 50^{\prime \prime}$ S e 49 $25^{\prime} 26^{\prime}$ ' W, altitude de 112 m) pertencente à Empresa Rio Deserto Ltda., Município de Siderópolis, Santa Catarina, que é um dos municípios da Bacia Carbonífera Catarinense que apresenta maior parte da sua área territorial degradada pela mineração de carvão (DE LUCA e GASTALDON, 1999).

O clima da região, segundo a classificação de Köppen, é do tipo Cfa, apresentando temperatura média normal anual variando entre 17,0 e $19,3^{\circ} \mathrm{C}$, índice pluviométrico entre 1.220 e $1.660 \mathrm{~mm}$ (EPAGRI, 2001) e cobertura vegetal original representada pela Floresta Ombrófila Densa (LEITE e KLEIN, 1990).

O lavador de carvão da Mina do Trevo entrou em operação em 1998, quando as Empresas Rio Deserto adquiriram áreas mineradas a céu aberto abandonadas e não recuperadas, ficando com a responsabilidade de recuperá-las como medida compensatória a instalação da Mina do Trevo. Parte dessa área era composta por antigas cavas de mineração a céu aberto que estavam alagadas com drenagem ácida de mina (DAM) e outra parte coberta por estéreis e rejeitos de mineração de carvão.

A partir de 2002, os trabalhos de recuperação dessas áreas foram iniciados, aproveitando as cavas resultantes da mineração a céu aberto alagadas com DAM. Para tanto, as referidas áreas foram preenchidas com rejeitos da mineração de carvão do fundo até aproximadamente a profundidade de $0,80 \mathrm{~m}$ da superfície, que foram cobertos com uma camada de $0,80 \mathrm{~m}$ de estéreis da mineração e recoberta por outra camada de $0,80 \mathrm{~m}$ de argila. A camada de argila recebeu a adição de matéria orgânica (cama de aviário), correção da acidez e da fertilidade, pela adição de calcário e adubo químico e o plantio de gramíneas e leguminosas em mudas. 
Após a construção do solo, a área foi compartimentada em várias subáreas que receberam denominações específicas à medida que a recuperação ambiental avançou.

Este estudo foi desenvolvido em duas áreas contíguas recuperadas, denominadas IV e VI, pela empresa responsável pelo passivo ambiental. A área IV sofreu o processo de construção do solo em 2002 e atualmente apresenta dois estratos vegetais, um inferior de até $0,30 \mathrm{~m}$ de altura e outro superior com até 2,00 m de altura. Aárea VI recebeu o mesmo processo de construção do solo em 2003, e hoje é verificada a formação de um estrato vegetal inferior de até $0,30 \mathrm{~m}$ e um superior de até $1,40 \mathrm{~m}$ de altura.

\subsection{Metodologia}

No centro de cada área de passivo ambiental recuperada (IV e VI), seguindo o seu eixo de maior comprimento, foi estabelecida uma transecção de 100 m de comprimento, em que foram lançadas alternadamente à direita e à esquerda, a intervalos de $10 \mathrm{~m}, 10$ transecções perpendiculares de $20 \mathrm{~m}$, sobre as quais foram coletadas, com o auxílio de um trado de rosca holandês, nove amostras de solo no horizonte superficial $(0-0,2 \mathrm{~m})$. As nove amostras de cada grupo de dois transectos consecutivos foram reunidas em uma amostra composta, quarteadas e requarteadas, reduzindo-se o universo amostral de 90 para cinco amostras de solo de cada área.

Foram analisados os seguintes parâmetros: argila, $\mathrm{pH}$, fósforo $(\mathrm{P})$, potássio $(\mathrm{K})$, matéria orgânica $(\mathrm{MO})$, alumínio (Al), cálcio $\left(\mathrm{Ca}^{2+}\right)$, magnésio $\left(\mathrm{Mg}^{2+}\right), \mathrm{H}+\mathrm{Al}$, conforme Tedesco et al. (1995) e soma das bases - SB, capacidade de troca catiônica e saturação das bases - V, de acordo com Oleynik et al. (1995). A interpretação dos dados seguiu as recomendações de EMBRAPA(2004).

Os resultados foram submetidos a cálculos estatísticos básicos como média, mediana, desvio-padrão e coeficiente de variação de acordo com Riboldi (1993), que considerou valores de coeficiente de variação acima de $25 \%$ como elevados. A diferença estatística dos teores médios dos parâmetros do solo analisado, entre as áreas estudadas, foi verificada por meio do teste $\mathrm{t}$ (CENTENO, 1999), a uma probabilidade de $95 \%$. Foi verificada, ainda, a existência de correlação entre os atributos do solo de uma mesma área, por meio do coeficiente de correlação de Pearson (r) (CENTENO, 1999), a uma probabilidade de $95 \%$. Para tanto, utilizouse o software BioEstat 3.0 (AYRES et al., 2003).

\section{RESULTADOS E DISCUSSÃO}

Os valores da média e mediana (Tabelas 1 e 2) de todos os atributos do solo analisado foram similares, apresentando todas as medianas com valores próximos à média. Esses resultados indicam que as medidas de tendência central não são dominadas por valores atípicos na distribuição (CAMBARDELLA et al., 1994), comportamento esse também encontrado por Corá et al. (2004).

As variáveis $\mathrm{MO}, \mathrm{Ca}^{2+}, \mathrm{Mg}^{2+}, \mathrm{H}+\mathrm{Al}, \mathrm{SB}$ e $\mathrm{V} \%$ na área IV (Tabela 1) e P, MO, $\mathrm{Mg}^{2+}, \mathrm{H}+\mathrm{Al}, \mathrm{SB}, \mathrm{CTC}$ e V\% na área VI (Tabela 2) apresentam coeficiente de variação alto (RIBOLDI, 1993). Os valores altos do coeficiente de variação indicam a ocorrência de locais nos solos construídos da Mina do Trevo com teores extremamente altos ou baixos das variáveis analisadas, o que indica heterogeneidade dos solos (CARVALHO et al., 2005), característica comum em solos recém-construídos, que ainda não atingiram o estado de equilíbrio.

O valor médio de argila da área IV (Tabela 1) e VI (Tabela 2) enquadram os solos na classe 3 (EMBRAPA, $2004)$, em que o teor de argila varia de 26 a $40 \%$, corroborando o relatado por Campos et al. (2003). Os valores médios de argila entre as duas áreas não apresentaram diferença estatística significativa $(\mathrm{P}=0,817)$. $\mathrm{O}$ teor de argila nessas áreas pode ser creditado ao desgaste das camadas superficiais do solo pela atividade erosiva da chuva que diminui seu teor e, por conseguinte, influencia o teor de matéria orgânica (RAIJ, 1983).

Os teores de matéria orgânica em ambas as áreas (Tabelas 1 e 2) foram considerados baixos, assim como nos trabalhos de Silva et al. (2004), e os valores médios das áreas IV e VI não apresentaram diferença estatística significativa $(P=0,723)$. Apesar de o teor de matéria orgânica ser semelhante nas duas áreas, era esperado nível mais alto na área IV, que foi recuperada há mais tempo e possui biomassa vegetal maior. No entanto, essa semelhança pode ser devida ao fato de a matéria orgânica aplicada na construção do solo da área VI ainda estar presente em maior quantidade.

Raij et al. (1987) destacaram que os teores de matéria orgânica do solo apresenta decorrem do equilíbrio de ganhos e perdas; em geral, valores mais altos desse atributo são encontrados em solos florestais, já nos solos construídos é comum o seu baixo teor, o que confirma os resultados encontrados desse parâmetro

R. Árvore, Viçosa-MG, v.33, n.4, p.665-674, 2009 
nas áreas estudadas, sobretudo em áreas que ainda não atingiram seu estado de equilíbrio no desenvolvimento do solo.

Sendo a porcentagem de argila e de matéria orgânica atributos que determinam as propriedades químicas, físicas e biológicas de um solo, como a estrutura, capacidade de retenção de água, disponibilidade de nutrientes para as plantas e a capacidade de reter cátions (RAIJ et al., 1987; LUCHESE et al., 2002), seus teores são de extrema importância para a manutenção da fertilidade desse solo.

$\mathrm{O}$ valor médio do $\mathrm{pH}$ em água foi considerado muito baixo em ambas as áreas (Tabelas 1 e 2), e seus valores médios apresentaram diferença estatística significativa $(\mathrm{P}=0,00001)$. Essa parece ser a tendência nos solos construídos em áreas de mineração de carvão a céu aberto, uma vez que Kämpf et al. (2000) e Campos et al. (2003) encontraram valores semelhantes. No entanto, ao avaliar os valores de $\mathrm{pH}$ dos solos construídos da Mina do Trevo, deve-se levar em consideração que os solos brasileiros são naturalmente ácidos, devido à própria pobreza em bases do material de origem ou a processos que favorecem a remoção de elementos básicos (LOPES et al., 1991). Esse fato é muito comum nos solos dos Estados do Rio Grande do Sul e de Santa Catarina (TEDESCO et al., 1995).

Campos et al. (2003) creditaram os baixos valores do $\mathrm{pH}$ encontrados em minas recuperadas no Município de Lauro Müller, Santa Catarina, à exposição de resíduos de carvão piritosos na camada superficial do solo. No entanto, nas áreas da Mina do Trevo não se observou esse fato até mesmo porque, durante o processo de recuperação, foram tomados cuidados para que ele não ocorresse. Assim, o pH muito baixo dessas áreas pode ser devido a uma acidificação natural que os solos sofrem ao longo do tempo (CORÁ et al., 2004).

Tabela 1 - Parâmetros estatísticos dos atributos dos solos construídos da área IV na Mina do Trevo, Siderópolis, SC

Table 1 -Statistical parameters for the attributes of the soils built in area IV of Mina do Trevo, Siderópolis, SC

\begin{tabular}{|c|c|c|c|c|c|}
\hline \multirow[t]{2}{*}{ Atributos do solo } & \multicolumn{5}{|c|}{ Área IV } \\
\hline & Mínimo e máximo & Média & Desvio padrão & Mediana & $\mathrm{CV} \%$ \\
\hline Argila (\%) & $30-34$ & 31,8 & 1,48 & 32 & 4,65 \\
\hline $\mathrm{pH}\left(\mathrm{H}_{2} \mathrm{O}\right)$ & $4,1-4,2$ & 4,18 & 0,04 & 4,2 & 0,95 \\
\hline $\mathrm{P}(\mathrm{ppm})$ & $4,8-7,8$ & 5,98 & 1,12 & 5,8 & 18,72 \\
\hline $\mathrm{K}(\mathrm{ppm})$ & $65-73$ & 70,4 & 3,20 & 72 & 4,54 \\
\hline M. orgânica (\%) & $0,4-1,0$ & 0,68 & 0,27 & 0,7 & 39,70 \\
\hline Al. $\left(\mathrm{cmol}_{\mathrm{c}} / 1\right)$ & $7,1-8,3$ & 7,64 & 0,52 & 7,4 & 6,80 \\
\hline $\mathrm{Ca}$ & $1,2-2,9$ & 1,92 & 0,63 & 1,8 & 32,81 \\
\hline $\mathrm{Mg}_{\text {troc }}\left(\mathrm{cmol}_{\mathrm{c}} / \mathrm{l}\right)$ & $0,6-1,0$ & 0,86 & 0,26 & 0,9 & 30,23 \\
\hline $\mathrm{H}+\mathrm{Al}\left(\mathrm{cmol}_{\mathrm{c}} / \mathrm{l}\right)$ & $21,76-43,35$ & 28,26 & 8,66 & 24,41 & 30,64 \\
\hline $\mathrm{SB}-\mathrm{S}\left(\mathrm{cmol}_{\mathrm{c}} / \mathrm{l}\right)$ & $1,98-4,3$ & 2,978 & 0,88 & 3 & 29,62 \\
\hline $\operatorname{CTC}\left(\mathrm{cmol}_{\mathrm{c}} / 1\right)$ & $24,16-45,33$ & 31,24 & 8,21 & 28,71 & 26,28 \\
\hline Sartur. Bases - V (\%) & $4,37-14,98$ & 10,142 & 3,79 & 10,49 & 37,37 \\
\hline
\end{tabular}

Tabela 2 - Parâmetros estatísticos dos atributos dos solos construídos da área VI na Mina do Trevo, Siderópolis, SC Table 2 -Statistical parameters for the attributes of the soils built in area IV in Mina do Trevo, Siderópolis, SC

\begin{tabular}{|c|c|c|c|c|c|}
\hline \multirow[t]{2}{*}{ Atributos do solo } & \multicolumn{5}{|c|}{ Área VI } \\
\hline & Mínimo e máximo & Média & Desvio padrão & Mediana & $\mathrm{CV} \%$ \\
\hline Argila (\%) & $30-33$ & 31,6 & 1,14 & 32 & 3,60 \\
\hline $\mathrm{pH}\left(\mathrm{H}_{2} \mathrm{O}\right)$ & $4,3-4,4$ & 4,38 & 0,04 & 4,4 & 0,91 \\
\hline $\mathrm{P}(\mathrm{ppm})$ & $3,2-9,3$ & 6,44 & 2,57 & 6,2 & 39,90 \\
\hline $\mathrm{K}(\mathrm{ppm})$ & $78-91$ & 84,2 & 5,93 & 82 & 7,04 \\
\hline M. orgânica (\%) & $0,4-1,0$ & 0,62 & 0,23 & 0,5 & 37,09 \\
\hline A1. $\operatorname{troc}\left(\mathrm{cmol}_{\mathrm{c}} / 1\right)$ & $5,7-7,5$ & 6,88 & 0,70 & 7,2 & 10,17 \\
\hline $\mathrm{Ca}_{\text {troc }}\left(\mathrm{cmol}_{\mathrm{c}} / 1\right)$ & $0,8-1,4$ & 1,02 & 0,23 & 0,9 & 22,54 \\
\hline $\mathrm{Mg}_{\text {troc }}\left(\mathrm{cmol}_{\mathrm{c}} / 1\right)$ & $1,0-2,7$ & 1,7 & 0,65 & 1,6 & 38,23 \\
\hline $\mathrm{H}+\mathrm{Al}\left(\mathrm{cmol}_{\mathrm{c}} / \mathrm{l}\right)$ & $8,69-34,45$ & 21,73 & 10,69 & 19,4 & 49,19 \\
\hline $\mathrm{SB}-\mathrm{S}\left(\mathrm{cmol}_{\mathrm{c}} / 1\right)$ & $2,05-4,38$ & 2,976 & 0,90 & 2,74 & 30,30 \\
\hline $\operatorname{CTC}\left(\mathrm{cmol}_{\mathrm{c}} / 1\right)$ & $13,07-37,72$ & 24,712 & 10,36 & 21,45 & 41,92 \\
\hline Sartur. Bases - V (\%) & $7,36-33,51$ & 14,838 & 10,84 & 9,56 & 73,09 \\
\hline
\end{tabular}


$\mathrm{O}$ pH do solo muito baixo pode resultar em problemas para a vegetação, uma vez que nessa situação, ele influencia a disponibilidade de nutrientes, podendo gerar condições inóspitas pelo aumento na disponibilidade e solubilidade de metais tóxicos (RAIJ et al., 1987; ALLOWAY, 1990; DIAS, 1998; WONG, 2003; PASCHKE et al., 2005) como o Al trocável (CORÁ et al., 2004).

Em termos nutricionais, para as plantas a faixa ideal de $\mathrm{pH}$ situa-se entre 5,6 e 6,2, pois a maioria dos nutrientes se encontra na forma solúvel e passível de ser absorvida por elas. Porém, uma gama de espécies tolera $\mathrm{pH}$ na faixa de 4,2 a 5,0, como os encontrados nas áreas IV e VI, pois elas apresentam capacidade de alterar o pH na região da rizosfera, além de possuírem mecanismos internos ao sistema radical que as fazem tolerar elevada acidez (DIAS, 1998). Cabe ressaltar, ainda, que outros fatores atuando isoladamente ou em conjunto com o pH são decisivos na colonização vegetal de uma área (ARAÚJO et al., 2005). Rodrigues et al. (2007) identificaram o pH como uma das variáveis com maior correlação com a distribuição da vegetação.

Entre as plantas que toleram solos ácidos, destacamse Pteridium aquilinum (L.) Jun, Baccharis trimera (Less.) DC., Eupatorium laevigatum Lam., Desmodium adscendens (Sw.) DC., Polygonum hydropiperoides L. e Diodia alata Nees \& C. Mart. (LORENZI, 2000), todas registradas nas áreas IV e VI, em levantamentos florísticos e fitossociológicos.

O teor de fósforo (P) na área IV foi considerado baixo (Tabela 1), enquanto na área VI variou de muito baixo a médio (Tabela 2), não sendo as diferenças entre as médias estatisticamente significativas $(\mathrm{P}=0,723)$. Resultados semelhantes foram encontrados por Silva et al. (2004) e Silva et al. (2006).

Nos processos de origem e transformação dos solos, o fósforo é um elemento removido em grandes quantidades (RAIJ, 1983). Como os solos construídos são essencialmente antropogênicos e seus processos pedogênicos muitas vezes são, ainda, incipientes (CAMPOS et al., 2003), os teores de fósforo nas áreas estudadas podem ser baixos devido à sua remoção.

Além de os teores de fósforo estarem sendo condicionados pela instabilidade físico-química do solo construído, o baixo teor de matéria orgânica e o baixo $\mathrm{pH}$ encontrados nessas áreas podem estar influenciando a presença de fósforo, pois esse elemento tem sua disponibilidade diminuída em condições de $\mathrm{pH}$ baixo (KABATA-PENDIAS e PENDIAS, 1992) e baixo teor de matéria orgânica (KIEHL, 1985; RAIJ et al., 1987; REINERT, 1998; CORÁ et al., 2004).

Os resultados expostos evidenciaram que o estabelecimento da vegetação nas áreas recuperadas da Mina do Trevo esteja sendo influenciado pelo baixo teor de fósforo, uma vez que a disponibilidade desse elemento pode ser fator químico determinante na recolonização vegetal, pois, quanto maior a sua disponibilidade, maior a diversidade de espécies vegetais (CORNEWELL e STONE, 1973). Em razão disso, Silva et al. (2006), analisando estéreis e rejeitos de mineração de ferro, sugeriram que em áreas mineradas que apresentam baixos teores de fósforo sejam adicionados fosfatos, a fim de garantir o desenvolvimento satisfatório das plantas durante o processo de revegetação.

As concentrações de cálcio na área IV (Tabela 1) variaram de baixo a médio, e na área VI (Tabela 2) foram baixos, evidenciando-se diferença estatisticamente significativa $(\mathrm{P}=0,018)$ entre as médias das duas áreas. O teor de magnésio tanto na área IV quanto na área VI (Tabelas 1 e 2) variou de médio a alto, evidenciando igualmente diferença estatística significativa $(\mathrm{P}=0,028)$. O teor de potássio na área IV (Tabela 1) foi classificado como médio e, na área VI (Tabela 2), variou de médio a suficiente, com diferença entre as médias das áreas estatisticamente significativa $(\mathrm{P}=0,0018)$.

Kämpf et al. (2000) encontraram em solos construídos sobre áreas mineradas de carvão no Rio Grande do Sul, com pH elevado, predomínio de Ca, o que indica que em solos com $\mathrm{pH}$ baixo o teor de $\mathrm{Ca}$ também é baixo, conforme detectado nos solos da Mina do Trevo. Foi detectada correlação significativa entre Ca e pH $(\mathrm{r}=-0,858)$ na área IV (Tabela 3$)$, comprovando a dependência entre esses dois parâmetros.

Os elementos cálcio, magnésio e potássio em solos tropicais e subtropicais, que são, na sua maioria, ácidos, normalmente se encontram em concentrações baixas; isso é natural, pois as perdas de bases são características do processo de acidificação dos solos (LUCHESE et al., 2002).

Gargantini et al. (1970) constataram que, nos mais de $93 \%$ dos solos cultiváveis do Estado de São Paulo, os teores de cálcio e magnésio situaram-se na faixa

R. Árvore, Viçosa-MG, v.33, n.4, p.665-674, 2009 
de baixo a médio, devido ao $\mathrm{pH}$ abaixo de 5,0, porém, apesar do baixo pH das áreas estudadas, o teor de magnésio no solo dessas variou de médio a alto, contrariando o relatado.

Apesar de as áreas de mineração tenderem a ser deficientes de potássio, cálcio e magnésio (PITCHEL et al., 1994) graças a processos de lixiviação e intemperização de minerais (PITCHEL et al., 1994; CAMPOS et al., 2003), os solos construídos da Mina do Trevo, com exceção de cálcio, apresentaram teores de magnésio e potássio variando de médio a alto e médio a suficiente, respectivamente. Possivelmente, isso se deve ao fato de as áreas terem sofrido o processo de recuperação recentemente, podendo não ter havido tempo suficiente para ocorrer o processo de lixiviação desses elementos do solo.

Scivittaro e Pillon (2006) recomendaram que em solos que apresentam teores de fósforo e de potássio muito baixos, baixos ou médios, como os encontrados nos solos construídos da Mina do Trevo, deve haver correção, a fim de elevar os teores desses nutrientes até o nível de suficiência.

Os teores médios de alumínio trocável e de $\mathrm{H}+$ Al na área IV (Tabela 1) foram maiores do que na área VI (Tabela 2), no entanto não se verificou diferença estatística significativa entre as médias desses teores ( $\mathrm{Al}: \mathrm{P}=0,089$ e $\mathrm{H}+\mathrm{AL}: \mathrm{P}=0,320)$. Em solos com valores de $\mathrm{pH}$ menores que 5,5, como os detectados nas áreas da Mina do Trevo, as formas tóxicas de alumínio são favorecidas, diminuindo a disponibilidade de nutrientes para as plantas e a saturação por bases, aumentando o alumínio trocável (R. MARTINAZZO, dados não publicados).

A correlação entre a SB, que é a soma de cátions que servem como nutrientes para as plantas, e Al foi significativa negativa em ambas as áreas (IV: $\mathrm{r}=-0,736$ e VI: $\mathrm{r}=-0,936)$, o mesmo ocorrendo com V\% e Al (IV: $r=-0,691$ e VI: $r=-0,38)$. Os valores de correlações descritos acima indicam que existe relação inversa entre os parâmetros considerados (Tabelas 3 e 4 ).

Os valores de alumínio trocável mostraram-se maiores na área IV, provavelmente devido à diminuição dos valores do pH e matéria orgânica nessa área em relação à área VI, pois o valor do alumínio trocável é influenciado pelo pH e teor de matéria orgânica no solo (FALLEIRO et al., 2003). A concentração de alumínio trocável no solo afeta, ainda, a disponibilidade de fósforo, potássio e cálcio (GOODLAND e FERRI, 1979), o que indica que os teores de alumínio dos solos construídos da Mina do Trevo podem estar influenciando a disponibilidade de cálcio e fósforo, o que resulta em baixos valores desses nessas áreas.

$\mathrm{Na}$ área IV foi verificada correlação significativa negativa entre $\mathrm{Al}$ e $\mathrm{K}(\mathrm{r}=-0,898)$ e $\mathrm{Al}$ e $\mathrm{Ca}(\mathrm{r}=-0,679)$ (Tabela 3). Já na área VI foi detectada correlação significativa positiva entre $\mathrm{Al} \mathrm{e} \mathrm{K}(\mathrm{r}=0,859)$ e significativa negativa entre $\mathrm{Al} \mathrm{e} \mathrm{Ca}(\mathrm{r}=-0,947)$ (Tabela 4). A existência de correlação significativa entre esses parâmetros evidencia que a disponibilidade desses elementos está fortemente atrelada.

Tabela 3 - Coeficiente de correlação (r) entre as variáveis consideradas na análise de fertilidade da área IV na Mina do Trevo, Siderópolis, SC. Valores em negritos são significativos a $\mathrm{P}<0,05$

Table 3 -Correlation coefficient ( $r$ ) among the variables considered in the fertility analysis of area IV in Mina do Trevo, Siderópolis, SC. Values in bold significant at $P<0,05$

\begin{tabular}{|c|c|c|c|c|c|c|c|c|c|c|c|c|}
\hline & Argila & $\mathrm{pH}$ & $\mathrm{P}$ & $\mathrm{K}$ & M.O. & $\mathrm{Al}$ & $\mathrm{Ca}$ & $\mathrm{Mg}$ & $\mathrm{Al}+\mathrm{H}$ & SB & СТC & V\% \\
\hline$\overline{\text { Argila }}$ & - & & & & & & & & & & & \\
\hline $\mathrm{pH}$ & 0,301 & - & & & & & & & & & & \\
\hline $\mathrm{P}$ & $-0,182$ & $-0,902$ & - & & & & & & & & & \\
\hline $\mathrm{K}$ & $-0,189$ & $-0,278$ & 0,430 & - & & & & & & & & \\
\hline M.O. & 0,595 & $-0,443$ & 0,501 & 0,460 & - & & & & & & & \\
\hline Al & 0,204 & 0,254 & $-0,549$ & $-0,898$ & $-0,317$ & - & & & & & & \\
\hline $\mathrm{Ca}$ & $-0,417$ & $-0,858$ & $\mathbf{0 , 8 7 9}$ & 0,715 & 0,454 & $-0,679$ & - & & & & & \\
\hline $\mathrm{Mg}$ & $-0,090$ & $-0,728$ & $\mathbf{0 , 9 2 3}$ & 0,710 & 0,608 & $-\mathbf{0 , 8 0 3}$ & $\mathbf{0 , 8 9 2}$ & - & & & & \\
\hline $\mathrm{Al}+\mathrm{H}$ & $-0,040$ & 0,248 & $-0,214$ & $-0,840$ & $-0,643$ & 0,529 & $-0,554$ & $-0,455$ & - & & & \\
\hline SB & $-0,331$ & $-0,835$ & $\mathbf{0 , 9 0 8}$ & $\mathbf{0 , 7 3 7}$ & 0,509 & $-0,736$ & 0,991 & 0,944 & $-0,543$ & - & & \\
\hline СТC & $-0,078$ & 0,172 & $-0,128$ & $-0,806$ & $-0,623$ & 0,479 & $-0,477$ & $-0,378$ & 0,995 & $-0,465$ & - & \\
\hline $\mathrm{V} \%$ & $-0,175$ & $-0,713$ & 0,729 & 0,845 & 0,673 & $-0,691$ & 0,922 & 0,840 & $-0,819$ & 0,922 & $-0,764$ & - \\
\hline
\end{tabular}

R. Árvore, Viçosa-MG, v.33, n.4, p.665-674, 2009 
Tabela 4 - Coeficiente de correlação (r) entre as variáveis consideradas na análise de fertilidade da área VI na Mina do Trevo, Siderópolis, SC. Valores em negritos significativos a $\mathrm{P}<0,05$

Table 4 - Correlation coefficient ( $r$ ) among the variables considered in the fertility analysis of area VI in Mina do Trevo, Siderópolis, $S C$. Values in bold significant at $P<0,05$

\begin{tabular}{|c|c|c|c|c|c|c|c|c|c|c|c|c|}
\hline & Argila & $\mathrm{pH}$ & $\mathrm{P}$ & $\mathrm{K}$ & M.O. & Al & $\mathrm{Ca}$ & $\mathrm{Mg}$ & $\mathrm{Al}+\mathrm{H}$ & SB & CTC & V\% \\
\hline Argila & - & & & & & & & & & & & \\
\hline $\mathrm{pH}$ & 0,294 & - & & & & & & & & & & \\
\hline $\mathrm{P}$ & $-0,240$ & $-0,620$ & - & & & & & & & & & \\
\hline $\mathrm{K}$ & 0,606 & 0,584 & $-0,720$ & - & & & & & & & & \\
\hline M.O. & $-0,238$ & $-0,889$ & 0,374 & $-0,815$ & - & & & & & & & \\
\hline Al & $-0,416$ & $-0,491$ & 0,346 & 0,859 & $\mathbf{0 , 7 3 0}$ & - & & & & & & \\
\hline $\mathrm{Ca}$ & 0,404 & 0,280 & 0,404 & 0,878 & $-0,622$ & $-0,947$ & - & & & & & \\
\hline $\mathrm{Mg}$ & 0,269 & 0,342 & 0,513 & 0,879 & $-0,706$ & $-0,924$ & 0,979 & - & & & & \\
\hline $\mathrm{A} 1+\mathrm{H}$ & 0,335 & $-0,469$ & 0,066 & 0,184 & 0,521 & 0,569 & $-0,366$ & $-0,424$ & - & & & \\
\hline $\mathrm{SB}$ & 0,316 & 0,221 & 0,487 & 0,886 & 0,688 & $-0,936$ & $\mathbf{0 , 9 9 0}$ & 0,998 & $-0,407$ & - & & \\
\hline СТC & 0,373 & $-0,455$ & 0,110 & 0,113 & 0,478 & 0,506 & $-0,292$ & $-0,350$ & 0,996 & $-0,333$ & - & \\
\hline $\mathrm{V} \%$ & 0,016 & 0,385 & 0,163 & 0,618 & $-0,643$ & $-0,908$ & $\mathbf{0 , 8 3 3}$ & $\mathbf{0 , 8 5 2}$ & $-0,815$ & 0,848 & $-0,767$ & - \\
\hline
\end{tabular}

Quando ocorre a redução dos teores de cátions como cálcio, magnésio e potássio, o alumínio trocável domina o complexo de troca, podendo promover limitações ao desenvolvimento da vegetação. Nas plantas, a toxicidade do alumínio causa paralisação do crescimento, engrossamento das raízes e altera a absorção e utilização de diversos nutrientes essenciais, especialmente o fósforo (MALAVOLTA, 1980).

A soma das bases (SB) em ambas as áreas variou de média a baixa (Tabelas 1 e 2), sem diferença estatística significativa entre os valores médios das duas áreas $(\mathrm{P}=0,997)$. O baixo valor da soma das bases indica a pouca disponibilidade de íons de cálcio, magnésio e potássio, revelando a maior atividade de hidrogênio nesses solos. Os baixos valores de soma das bases e valores de $\mathrm{pH}$ muito baixos, como os encontrados nas áreas da Mina do Trevo, sugerem um solo com baixa fertilidade, conforme destacaram Corá et al. (2004).

A capacidade de troca catiônica (CTC) em ambas as áreas foi alta (Tabelas 1 e 2) com valores médios sem diferença estatística significativa $(\mathrm{P}=0,301)$. Os solos com alta CTC devem apresentar alto teor de argila ou de matéria orgânica (LOPES e GUILHERME, 1992; GONÇALVES et al., 2003). Dessa forma, a alta CTC dos solos construídos das áreas estudadas pode ser atribuída ao teor de argila, uma vez que nas duas áreas o teor de matéria orgânica foi baixo, confirmando o relatado por Wutke e Camargo (1975), que afirmaram que a porcentagem de argila é um dos principais fatores responsáveis pela CTC do solo.
Os valores da CTC são influenciados pelas variações de cálcio e magnésio, os quais são de grande importância no tocante à fertilidade do solo, uma vez que indicam a capacidade desse solo em adsorver cátions em forma trocável, que em geral, servirão de nutrientes para as plantas (TEDESCO et al., 1995; CHAVES et al., 1998). Quando a CTC do solo está ocupada por cátions como cálcio, magnésio e potássio, ele pode ser considerado rico em nutrientes, porém se a CTC estiver ocupada por cátions potencialmente tóxicos, como o $\mathrm{H}^{+} \mathrm{e}^{3+}$, caracteriza um solo pobre, pois restam poucas cargas para os cátions nutrientes, refletindo em uma saturação por bases baixa.

A saturação por bases (V\%) em ambas as áreas foi considerada como muito baixa (Tabelas 1 e 2), com valores médios sem diferença estatística significativa $(\mathrm{P}=0,387)$. A saturação por bases muito baixa e o baixo valor da soma das bases revelam que a maior porcentagem de cargas negativas está ocupada por $\mathrm{H}^{+}$e $\mathrm{Al}^{3+}$, que são potencialmente tóxicos. Zocche (dados não publicados) verificou que a elevada CTC em solos construídos em áreas de mineração de carvão a céu aberto refletia a elevação nos valores de $\mathrm{H}$ e $\mathrm{Al}$ trocáveis presentes no solo.

O alto valor da CTC evidenciado nos solos construídos na Mina do Trevo se deve, portanto, a presença de íons tóxicos como o $\mathrm{H}^{+}$e $\mathrm{Al}^{3+}$ e não de cálcio, magnésio e potássio, sugerindo baixa fertilidade desses solos. $\mathrm{O}$ predomínio de íons de $\mathrm{Al}$ e poucos íons de cálcio, magnésio e potássio é comum nos solos brasileiros, devido à sua acidez natural (MELLO et al., 1989).

R. Árvore, Viçosa-MG, v.33, n.4, p.665-674, 2009 
Diante do exposto, deve-se salientar que os índices de concentração dos atributos do solo aqui utilizados para análise da fertilidade são baseados em critérios agronômicos padronizados para solos agrícolas e não para áreas influenciadas pela mineração, devendo ser seguido com cautela quando da análise de solos construídos. Deve-se considerar, ainda, que a disponibilidade de nutrientes e a velocidade de decomposição da matéria orgânica são influenciadas tanto pela amplitude térmica (que varia na região de 17 a $19,3^{\circ} \mathrm{C}$ - média anual), quanto pela evapotranspiração do solo, umidade relativa e intensidade luminosa, as quais variam sazonalmente na latitude em que foi realizado este estudo.

Apesar do exposto, Silva et al. (2004) assinalam que, em virtude da carência de parâmetros específicos, os resultados de trabalhos que levem em consideração parâmetros físicos e a fertilidade de solos influenciados pela mineração são de extrema importância. Deve-se ressaltar ainda que, para que um solo seja considerado fértil, além de conter quantidades suficientes de nutrientes essenciais às plantas, tem que estar livre de substâncias tóxicas e apresentar propriedades físicas satisfatórias (MELLO et al., 1989).

\section{CONCLUSÕES}

$\mathrm{Na}$ avaliação dos efeitos da reconstrução do solo em parâmetros químicos, em condições de campo e na região sul de Santa Catarina, pode-se concluir que:

- Solos de áreas de mineração e construídos em tempos diferentes, quanto aos parâmetros analisados, são muito similares, indicando que o tempo de recuperação não afeta severamente a sua fertilidade.

- Baixos teores de matéria orgânica e fósforo e elevada acidez, em solos reconstruídos de locais de mineração de carvão, podem apresentar restrições ao desenvolvimento de plantas.

- Os baixos valores da soma das bases, de pH, da saturação por bases e de fósforo, revelam que a maior parte do complexo de troca do solo está ocupada por cátions tóxicos de $\mathrm{H}$ e Al, refletindo baixa fertilidade do solo.

\section{AGRADECIMENTOS}

Ao Conselho Nacional de Desenvolvimento Científico e Tecnológico (CNPq), pela concessão da bolsa ao primeiro autor; e às Empresas Rio Deserto Ltda., pela liberação da área para o desenvolvimento desta pesquisa.

\section{REFERÊNCIAS}

ALEXANDRE, N. Z. Diagnóstico ambiental da Região carbonífera de Santa Catarina: degradação dos recursos naturais. Revista Tecnologia e Ambiente, v.5, n.2, p.35-50, 1999.

ALLOWAY, B. J. Heavy metals in soils. New York: John Willy, 1990. 339p.

ARAÚJO, F. S.et al. Florística da vegetação arbustivo-arbórea colonizadora de uma área degradada por mineração de caulim, em Brás Pires, MG. Revista Árvore, v.29, n.6, p.983-992, 2005.

AYRES, M.; AYRES JUNIOR, M.; SANTOS, A. S. BioEstat 3.0: aplicações estatísticas nas áreas das ciências biológicas e médicas. Belém: Sociedade Civil Mamirauá, 2003. 193p.

BRASIL. Ministério do Meio Ambiente. Resolução CONAMA n. 001 de 23 de janeiro de 1986. Confere o artigo 48 do Decreto $n^{\circ} 88.351$, de $1^{\circ}$ de junho de 1983, para efetivo exercício das responsabilidades que lhe são atribuídas pelo artigo 18 do mesmo decreto, e Considerando a necessidade de se estabelecerem as definições, as responsabilidades, os critérios básicos e as diretrizes gerais para uso e implementação da Avaliação de Impacto Ambiental como um dos instrumentos da Política Nacional do Meio Ambiente. Coleção de leis [do] Ministério do Meio Ambiente. Disponível em: < http://www.mma.gov.br/port/conama/res/res86/ res0186.html> Acesso em: 20 set. 2005.

CAMBARDELLA, C. A. et al. Field-scale variability of soil properties in central Iowa soils.

Soil Science Society of America Journal, v.58, n.5, p.1501-1511, 1994.

CAMPOS, M. L.; ALMEIDA, J. A.; SOUZA, L. S. Avaliação de três áreas de solo construído após mineração de carvão a céu aberto em Lauro Müller, Santa Catarina. Revista Brasileira de

Ciência do Solo, v.27, n.6, p.1123-1137, 2003.

CARVALHO, D. B. et al. Fertilidade do solo em integração lavoura-pecuária na região de Guarapuava/ PR. Revista Acadêmica: Ciências Agrárias e Ambientais, v.3, n.1, p.57-65, 2005.

CEnteno, A. J. Curso de estatística aplicada à biologia. Goiânia: Universidade Federal de Goiás, 1999. 234p. 
CHAVES, L. H. G. et al. Avaliação da fertilidade dos solos das várzeas do município de Sousa, PB. Revista Brasileira de Engenharia Agrícola e Ambiental, v.2, n.3, p.262-267, 1998.

CORÁ, J. E. et al. Variabilidade espacial de atributos do solo para adoção do sistema de agricultura de precisão na cultura de cana-deaçúcar. Revista Brasileira de Ciência do Solo, v.28, n.6, p.1013-1021, 2004.

CORNWELL, S. M.; STONE, E. L. Spoil type lithology and foliar composition of Betul populifolia. In: HUTNIK, R. J.; DAVIS, G. (Eds.) Ecology and reclamation of devastated land. New York: Gordon e Breach, 1973. v.1.p.105-120.

DELUCA, F. J.; GASTALDON, M. C. Desenvolvimento sustentável e a recuperação das áreas degradadas abandonadas pela mineração de carvão na região Sul do Estado de Santa Catarina. Revista Tecnologia e Ambiente, v.5, n.2, p.19-33, 1999.

DIAS, L. E. Caracterização de substratos para fins de recuperação de áreas degradadas. In: DIAS, L. E.; MELlO, J. W. V. (Eds.) Recuperação de área degradada. Viçosa, MG: Universidade Federal de Viçosa, 1998. p.27-44.

EMPRESA BRASILEIRA DE PESQUISA AGROPECUÁRIA - EMBRAPA. Manual de adubação e de calagem para os estados do Rio Grande do Sul e de Santa Catarina. Porto Alegre: Sociedade Brasileira de Ciências do Solo/Núcleo Regional Sul, 2004.

EMPRESA DE PESQUISAS AGROPECUÁRIAE DE EXTENSÃO RURAL DE SANTA CATARINA -

EPAGRI. Secretaria de Estado do Desenvolvimento Rural e da Agricultura. Dados e informações bibliográficas da Unidade de Planejamento Regional Litoral Sul Catarinense - UPR 8. Florianópolis: 2001.

FALLEIRO, R. M. et al. Influência dos sistemas de preparo na propriedades químicas e físicas do solo. Revista Brasileira de Ciência do Solo, v.27, n.6, p.1097-1104, 2003.

GAIVIZZO, L. B. et al. Potencial poluidor de rejeitos carboníferos. II - efeitos da recuperação com camadas de solo sobre as plantas e a população microbiana. Ciência Rural, v.32, n.6, p. 955-961, 2002.
GAIVIZZO, L. B.; VIDOR, C.; TEDESCO, M. J.

Recuperação de áreas utilizadas para depósitos de rejeitos de minas de carvão. In: Carvão e meio ambiente: Centro de Ecologia da UFRGS. Porto Alegre: Universidade Federal do Rio Grande do Sul, 2000. p.480-491.

GARGANTINI, H.; COELHO, F. A. S.; SOARES, F. V. E. Levantamento de fertilidade dos solos do Estado de São Paulo. Campinas: Instituto Agronômico de Campinas, 1970. 32p.

GONÇALVES, J. M. L. et al. Recuperação de solos degradados. In: KAGEYAMA, P.Y. et al (Orgs.).

Restauração ecológica de ecossistemas naturais. Botucatu: FEPAF, 2003. p.111-163.

GOODLAND, R.; FERRI, M. G. Ecologia do Cerrado. Belo Horizonte: Itatiaia, Edusp, 1979. 193p.

KABATA-PENDIAS, A.; PENDIAS, H. Trace element in plants and soils. Boca Raton: CRC Press, 1992. 315p.

KAMPF, N. et al. Solos construídos em áreas de mineração da bacia carbonífera. In: Carvão e meio ambiente: Centro de Ecologia da UFRGS. Porto Alegre: Universidade Federal do Rio Grande do Sul, 2000. p.596-640.

KÄMPF, N.; SCHNEIDER, P.; GIASSON, E. Propriedades pedogênese e classificação de solos construídos em áreas de mineração na Bacia Carbonífera do Baixo Jacuí. Revista Brasileira de Ciência do Solo, v.21, n.1, p.79-88, 1997.

KIEHL, E. J. Fertilizantes orgânicos.

Piracicaba: Agronômica Ceres, 1985. 492p.

LEITE, P. F.; KLEIN, R. M. Vegetação. In: Instituto Brasileiro de Geografia e Estatística Geografia do Brasil, 1990. v.2. p.113-150.

LOPES, A. S.; GUILHERME, L. R. G. Interpretações de análise do solo: conceitos e operações. São Paulo: Associação Nacional Para a Difusão de Adubos, 1992. (Boletim Técnico, 2).

LOPES, A. S.; SILVA, M. C.; GUILHERME, L. R. G. Acidez do solo e calagem. São Paulo: Associação nacional Para a Difusão de Adubos, 1991. (Boletim Técnico, 1).

R. Árvore, Viçosa-MG, v.33, n.4, p.665-674, 2009 
LORENZI, H. Plantas daninhas do Brasil: terrestres, aquáticas, parasitas e tóxicas. Nova Odessa: Instituto Plantarum, 2000. 608p.

LUCHESE, E. B.; FAVERO, L. O. B.; LENZI, E. Fundamentos da química do solo: teoria e prática. 2.ed. Rio de Janeiro: Freitas Bastos, 2002. 182p.

MALAVOLTA, E. Elementos de nutrição mineral de plantas. São Paulo: Agronômica Ceres, 1980. 251p.

MELLO, F. A. F. et al. Fertilidade do solo. Piracicaba: Nobel, 1989. 400p.

MIAO, Z.; MARRS, R. Ecological restoration and land reclamation in open-costa mines in Shanxi Province, China. Journal of Environmental Management, v.59, n.3, p.205-215, 2000.

OLEYNIK, J. et al. Análises de solo: tabelas para transformação de resultados analíticos e interpretação de resultados. Curitiba: EMATER Paraná, 1995. (Informação Técnica, 31).

PASCHKE, M. W.; VALDECANTOS, A.; REDENTE, E. F. Manganese toxicity thresholds for restoration grass species. Environmental Pollution, v.135, n.22, p.3131-322, 2005.

PINTO, L. F. S. Potencial de acidificação e de neutralização das materiais geológicos para a composição do solo construído em áreas de mineração de carvão. 1997. 186f. Tese (Doutorado em Ciência do Solo) - Universidade Federal do Rio Grande do Sul, Porto Alegre, 1997.

PITCHEL, J. R.; DICK, W. A.; SUTTON, P. Comparison amendments and management pratices for long-term reclamation of abandoned mine lands. Journal Environmental Quality, v.23, n.1, p.766-772, 1994.

RAIJ, B.van. Avaliação da fertilidade do solo. Piracicaba: Instituto do Potássio e Fósforo, 1983. 142p.

RAIJ, B.van et al. Análise química do solo para fins de fertilidade. Campinas: Fundação Cargill, 1987. 170p.
REINERT, D. J. Recuperação de solos em sistemas agropastoris. In: DIAS, L. E.; MELLO, J. W. V. Recuperação de áreas degradadas. Viçosa, MG: Universidade Federal de Viçosa, 1998. p.163-176.

RIBOLDI, J. Elementos básicos de estatística. Cadernos de matemática e estatística. Porto Alegre: Instituo de Matemática,

Universidade Federal do Rio Grande do Sul, 1993. (Série B: Trabalho de apoio didático).

RODRIGUES, L. A. et al. Efeitos de solos e topografia sobre a distribuição de espécies arbóreas em um fragmento de floresta Estacional Semidecidual em Luminárias, MG. Revista Árvore, v.33, n.1, p.25-35, 2007.

SANCHEZ, J. C. D.; FORMOSO, M. L. L. Utilização do carvão e meio ambiente. Porto Alegre: CIENTEC, 1990. 34p.

SCIVITTARO, W. B.; PILlON, C. N. Calagem e adubação para a cultura da mamona no sul do Brasil. Pelotas: Empresa Brasileira de Pesquisa Agropecuária, 2006. p.1-8. (Comunicado Técnico Embrapa, 150).

SILVA, G. P. et al. Caracterização química, física e mineralógica de estéreis e rejeito de mineração de ferro da mina de Alegria, Mariana-MG. Pesquisa

Agropecuária Tropical, v.36, n.1, p.45-52, 2006.

SILVA, S. R. et al. Caracterização de rejeito de mineração de ouro para avaliação de solubilização de metais pesados e arsênio e revegetação local.

Revista Brasileira de Ciência do Solo, v.28, n.1, p.189-196, 2004.

TEDESCO, M. J. et al. Análise de solo, plantas e outros materiais. Porto Alegre, Universidade Federal do Rio Grande do Sul, 1995. 188p (Boletim Técnico, 5).

WONG, M. H. Ecological restoration of mine degraded soils, with emphasis on metal contaminated soils. Chemosphere, v.50, n.66, p.775-780, 2003.

WUTKE, A. C.; CAMARGO, O. A. Adsorção e troca iônica. In: MONIZ, A. C. (Ed.) Elementos de pedologia. São Paulo: Polígono, 1975. p.125-147. 